New TA-Project

\section{A New Approach to TA} from Australia

By A. Wendy Russell, University of Wollongong, and Frank Vanclay, University of Tasmania, Australia

Technology Assessment in Social Context (TASC) is a research project funded by the Australian Research Council from 2006 to 2008. Its primary aim is to develop a framework for technology assessment (TA) for Australia. Drawing on international TA practice and 'Social Impact Assessment', TASC also presents a new TA approach for the international TA community. The novelty of TASC is its emphasis on the social nature of technology and the influence of the social context on the nature and impacts of technology. TASC provides a constructive, social systems approach to (1) assess technology in social context and (2) shape technology and social contexts through information, interaction and dialogue.

\section{A new framework}

The TASC project responds to the lack of formal Technology Assessment (TA) in Australia, and the need for tools and institutions to inform policy, resolve disputes and stimulate broad deliberation about new technologies. The primary aim of the project is to develop a TA framework that is tailored to the Australian socio-political context, but it should be of interest to other countries and to the international TA community because of the increased attention given to the social context in the TASC framework. By framework we mean a structure for organising ideas, processes and approaches to give conceptual clarity and procedural guidance. The framework will comprise:

- a description of procedural phases, including scouting, screening, scoping, assessment, communication and participation, and evaluation,

- a toolbox of TA approaches and TA methods,

- criteria for assessing quality,
- additional resources - case studies, indicative impacts list,

- criteria for institutionalisation.

\section{Research plan}

Development of the framework involves a review of international TA, a review of the policy context in Australia, and one or more case studies. The international review is based on a trip conducted in 2006, when Wendy Russell and Frank Vanclay visited a number of TA institutions and practitioners in Europe and the US. The review of the Australian context involves the input of a partner investigator, Heather Aslin, who works for the Bureau of Rural Sciences, an Australian Government agency, and a reference group representing various relevant bodies and interests. We are also conducting an analysis of TA-like activities conducted in Australia, including the advantages and disadvantages of different approaches and institutional settings. The first case study is being conducted by our $\mathrm{PhD}$ student, Julie Kimber, who is considering social dimensions of the genetic engineering of crop plants to produce omega-3 fatty acids.

\section{Social TA}

The project will draw on insights from Social Impact Assessment (SIA) and will investigate the overlap between SIA and TA. In particular, a broad understanding of 'the social' dimension $^{1}$, and a recognition that design, use and governance of technology are social processes, means that a social systems approach can provide a comprehensive frame for TA. ${ }^{2}$

TASC recognises the importance of participation, and seeks to include participatory methods in thoughtful, critical and appropriate ways. The 'technology (assessment) in social context' approach sees all social actors, including members of the public, technology designers and decision makers, as part of the social context, and therefore as stakeholders or potential stakeholders. TASC also sees a critical role for social research expertise. TASC aims for assessment that is scientifically rigorous (supported by evidence) and socially robust (meaningful and representative). In this sense, TASC 
can be seen to take a 'critical rationality' approach (Grunwald 2005).

\section{Expected contribution}

TASC aims to provide a richer picture of technologies in social context, and of the associated landscape of values, allowing stakeholders to understand the technology and each other's perspectives and values. TASC may thus assist in reducing value conflicts and promoting constructive debate in technology discussions. TASC recognises that the various stakeholders have particular information needs (e.g. scientists need information about the social setting, lay participants need information about the technology), and that each group provides expertise and insights into particular aspects of technology in context. The TASC process is thus inclusive and promotes dialogue between stakeholders. This creates a setting for deliberation and a process to improve decision-making, decision implementation and ongoing evaluation.

In changing the way people think about technology, TASC has the potential to change the premises behind technology design, the intentions behind technology use, and the priorities around technology governance. In addition to contributing to decision-making, TASC also promotes direct changes to the technology (through changes in design and use), and to the social context (through changes in understandings, attitudes and choices, relationships and social arrangements) to improve outcomes.

More information will be available about the TASC project over time from the TASC website: http://www.utas.edu.au/ruralcommuni ties/TASC/

\section{Notes}

1) The meaning of 'social dimension' relates to things that affect people's way of life, their culture, their community, their political systems, their environment, their health and wellbeing, their personal and property rights, and their fears and aspirations (Vanclay 2003).

2) This approach is similar to the 'social relations' model described by Bereano (1997).

\section{References}

Bereano, P.L., 1997: Reflections of a ParticipantObserver: The Technocratic/Democratic Contradiction in the Practice of Technology Assessment. In: Technological Forecasting and Social Change 54 (1997), pp. 163-175

Grunwald, A., 2005: Rationality in an Uncertain World: The Vision of Sustainable Development as an Adequate Answer? In: Banse, G.; Hronszky, I.; Nelson, G. (eds.): Rationality in an Uncertain World. Berlin, pp. 11-36

Vanclay, F., 2003: International Principles for Social Impact Assessment. In: Impact Assessment and Project Appraisal 21/1 (2003), pp. 5-11

\section{Contact}

Dr. A. Wendy Russell

University of Wollongong

School of Biological Sciences

189 Miller st, O Connor

ACT 2602, Australia

E-Mail: Wendyr@uow.edu.au 